\title{
Anxiety Profile in Children and Adolescents with Stuttering
}

\author{
Fatma El-Zahraa A. Kaddah ${ }^{1,2}$, Tamer A. Mesallam ${ }^{3,4}$, Rasha M. Shoeib ${ }^{1}$, Ahmed \\ Abdelhamid ${ }^{1,5}$
}

Original

${ }^{1}$ Phoniatrics Unit, Otorhinolaryngology Department, College of Medicine, Ain Shams Article University, Cairo, Egypt, ${ }^{2}$ Department of Otorhinolaryngology \& Allied Sciences, Dr. Soliman Fakeeh Hospital, Jeddah, KSA, ${ }^{3}$ Research Chair of Voice, Swallowing, and Communication Disorders, ENT Department, College of Medicine, King Saud University, ${ }^{4}$ Department of Otolaryngology, Head and Neck Surgery, King Saud University, Riyadh, KSA, ${ }^{5}$ Department of Otorhinolaryngology, College of Medicine, Imam Abdulrahman Bin Faisal University, P.O. Box 1982, Dammam, Saudi Arabia).

\begin{abstract}
Objectives: To compare anxiety levels in children and adolescents who stutter with non-stuttering subjects. Methods: The study included 35 stuttering patients and 35 age and gender-matched control group. Both groups underwent subjective assessment of anxiety using Taylor anxiety scale. Stuttering severity was assessed in the patients' group using the Arabic Stuttering Severity Instrument (A-SSI).

Results: Stuttering group showed significantly higher anxiety levels than control subjects $(p<0.0001)$. Taylor Anxiety scale results were significantly higher $(P<0.05)$ in female stuttering patients than male patients. Anxiety scores showed a statistically significant negative correlation with age of onset of stuttering $(r=-0.48, p=0.002)$ and a statistically significant positive correlation with duration of stuttering $(\mathrm{r}=0.329, \mathrm{p}=0.046)$.

Conclusion: Children and adolescents with stuttering have significantly higher anxiety levels compared to control subjects. High anxiety scores were significantly related to early onset and longer duration of stuttering.
\end{abstract}

Key Words: Adolescents, anxiety, stuttering, stuttering severity instrument.

Received: 19 June 2019, Accepted: 15 July 2019

Corresponding Author: Abdelgoad, Ahmed Abdelhamid, PhD , Unit of Phoniatrics , Otorhinolaryngology Department, Faculty of Medicine, Ain Shams University, Cairo, Egypt. Tel.: 966568360191, E-mail: dr_mido1976@yahoo.com

ISSN: 2090-0740, July 2020 Vol.21, No.2

\section{INTRODUCTION}

The Diagnostic and Statistical Manual of Mental Disorders defines Childhood-Onset Fluency Disorder (Stuttering) as a condition characterized by disturbances in the normal fluency and time patterning of speech that are inappropriate for the individual's age and language skills, and persist over time. The onset of symptoms is usually in the early developmental period ${ }^{[1]}$. Stuttering can be presented by sounds or syllables redundancies or as a discourse stops between sounds, syllables or words that might be associated with some auxiliary practices including eye, jaw twitching, head and appendages developments ${ }^{[2,3]}$.

Around 5\% of all kids experience a time of disfluency that endures six months or more. Seventy-five percent of those will recover by late youth, leaving around $1 \%$ with a long haul issue ${ }^{[4]}$.

Anxiety is described by feeling of strain and stressed attitude, which may be accompanied by physical changes like expanded pulse. Individuals with nervousness issue may likewise have some physical indications, for example, sweating, trembling, or dizziness ${ }^{[5]}$. Encountering periodic uneasiness is an ordinary piece of life. Individuals with uneasiness issue much of the time have extreme, uncontrolled and constant stress and anxiety over ordinary circumstances $^{[6]}$. Barlow ${ }^{[7]}$ defines anxiety as "a futureoriented mood state in which one is ready or prepared to attempt to cope with upcoming negative events".

The overall view in the twentieth century expected that stuttering was created by mental variables, for example, nervousness, as opposed to a physiological cause. Despite the fact that it was trusted that nervousness brought on stuttering, there is no proof supporting this ${ }^{[8]}$.

Fears have been appeared to be higher in kids who stutter than in youngsters who don't, and these feelings increase with age ${ }^{[9]}$. Lessened capacity to talk fluently attributable to a person with speech issues can restrict professional prospects ${ }^{[10]}$ and many individuals with a moderate to severe stuttering perceive it as a barrier to effective communication and therefore as a negative life event $^{[11]}$ 
Many stuttering patients might present by features that look-like anxiety features. Clinicians are usually concerned to withdraw primary anxiety disorders during history taking and in many cases they consider that these anxiety features are related to secondary manifestations of stuttering.

\section{Aims of the study:}

To The aim of this study was to compare anxiety levels in children and adolescents who stutter with normal subjects and to highlight the correlations between anxiety and different factors in stuttering patients.

\section{SUBJECTS AND METHODOLOGY:}

After obtaining the Institutional Review Board approval, the study was carried out on 35 stuttering patients presented to the Phoniatrics Clinic at the Otorhinolaryngology \& Allied Sciences Department between March 2016 and August 2017 with non-fluent speech utterance. They were all selected to have an average IQ and with no history of previous speech therapy. Patients in the study group were subjected to a multidimensional protocol for objective and subjective assessment of stuttering including:

1. Parent's interview and full history taking giving special consideration to age of onset and the duration of stuttering.

2. Auditory perceptual assessment of both automatic speech and spontaneous speech for detection of the core behavior of stuttering.

3. Assessment of the stuttering severity that was performed using the Arabic versions of stuttering severity instrument (A-SSI) ${ }^{[12]}$ which was adopted from the original version the Stuttering Severity Instrument $(\mathrm{SSI})^{[13-15]}$. A stuttering severity score of $0-20$ is considered very mild, from $21-24$ is mild, 25-31 is moderate, and 32-35 is severe, while $36-45$ is considered very severe.

Subjective assessment of anxiety was done using a double-translated form of Taylor Anxiety Scale ${ }^{[16]}$ that consisted of 55 items and was given as a printed Arabic questionnaire form to each subject or his/her parents based on age. Clear instructions were given to patients and their caregivers to select an answer to each item by encircling either true or false beside each item. Data were collected for each subject by calculating the numbers of items answered by "true" for each subject. Where total scores below 16 were considered normal, scores ranged 16-25 were considered mild anxiety, scores from $26-36$ were considered moderate anxiety while those got a score more than 36 were considered to have severe anxiety.

Thirty-five age \& gender-matched subjects were invited to participate in the study as a control group. All of them have no current or past history of language or speech problems and they were all selected from individuals accompanying patients at the clinics. They were all subjected to Taylor anxiety scale that was applied and calculated by the same methods as for the study group.

\section{Statistical Analysis:}

Statisticalanalyseswereperformedusing SPSS statistical package, version 18 (IBM Corporation, Chicago, Illinois, USA). Quantitative variables were presented as means and SD. Qualitative variables were presented as numbers and percentage. Parametric variables were compared using the independent sample t-test. Chi-square $(\chi 2)$ test was used to compare between proportions. Nonparametric Correlation between parametric variables was as ascertained using Pearson correlation coefficient while Spearman rank correlation coefficient was used to test the correlation between non-parametric variables was ascertained using. $P$ values less than 0.05 were considered significant.

\section{RESULTS:}

This study included 35 patients with stuttering with an age range of 10 years to 20 years \& 3months and a mean age $\pm \mathrm{SD}$ of $14.65 \pm 2.53$ year. Twenty-two subjects $(62.9 \%)$ were males and 13 subjects $(37.1 \%)$ were females (Table1). Eighteen subjects $(51.4 \%)$ had positive family history of stuttering while $17(48.6 \%)$ had negative family history of stuttering.

The age of onset of stuttering ranged from 3 years to 11 years with a mean age \pm SD of $5.9 \pm 2.1$ years. The duration of stuttering ranged from 3 years and 2 months to 14 years with a mean duration \pm SD of $8.6 \pm 2.6$ years.

According to Bloodestein Classification of stuttering ${ }^{[17]}$, 15 subjects $(42.9 \%)$ have grade II, 19 subjects $(54.3 \%)$ have grade III, and 1 subject (1.8\%) has grade IV. Regarding the SSI, the study group subjects had stuttering of different severity ranged from $21-46$ with a mean score \pm SD of 33.5 \pm 7.6 . Eight subjects $(22.9 \%)$ had mild stuttering, 5 subjects $(14.3 \%)$ had moderate stuttering, 10 subjects $(28.5 \%)$ had severe stuttering and 12 subjects $(34.3 \%)$ had very severe stuttering.

Regarding the Taylor Anxiety Scale, the scores of the study group ranged from 7-41 with a mean score \pm SD of $25.2 \pm 10.9$. There were 11 subjects $(31.4 \%)$ with normal scores, 6 subjects (17.1\%) with mild anxiety, 14 subjects $(40 \%)$ with moderate anxiety and 4 subjects $(11.4 \%)$ with scores reflecting severe anxiety.

The control group included 35 non-stutterer subjects with an age range of 10 years to 19 years $\& 4$ months with a mean age $\pm \mathrm{SD}$ of $13.9 \pm 3$ years. They were 22 male subjects $(62.9 \%)$ and $13(37.1 \%)$ female subjects (Table1) 
The control group had Taylor Anxiety scores ranged from $5-26$ and a mean score \pm SD of $16.1 \pm 4.3$ (Table1). Eighteen subjects (51.4\%) had normal scores, 15 subjects (42.9\%) showed mild anxiety while 2 subjects (5.7\%) had moderate anxiety.
Comparisons between the study group and the control group regarding both age and gender showed no significant results $(p>0.05) \quad$ (Table1). Meanwhile comparisons between the 2 groups regarding the Taylor Anxiety Scale revealed highly significant difference $(p<0.0001)$ (Table1).

Table 1: Comparison between study group and control group regarding demographic data and Taylor Anxiety Scale

\begin{tabular}{|c|c|c|c|c|c|}
\hline Variables & \multicolumn{2}{|c|}{$\begin{array}{l}\text { Stuttering group } \\
\qquad(\mathrm{N}=35)\end{array}$} & \multicolumn{2}{|c|}{$\begin{array}{l}\text { Control group } \\
(\mathrm{N}=35)\end{array}$} & $P$ value \\
\hline \multirow{2}{*}{ Gender N (\%) } & Male & Female & Male & Female & \multirow{2}{*}{$>0.05$} \\
\hline & $22(62.9 \%)$ & $13(37.1 \%)$ & $22(62.9 \%)$ & $13(37.1 \%)$ & \\
\hline $\begin{array}{c}\text { Age } \\
\text { Mean } \pm \text { SD (years) }\end{array}$ & \multicolumn{2}{|c|}{$14.7 \pm 2.5$} & \multicolumn{2}{|c|}{$13.9 \pm 3$} & $>0.05$ \\
\hline $\begin{array}{l}\text { Taylor Anxiety } \\
\text { Scale Mean } \pm \text { SD }\end{array}$ & \multicolumn{2}{|c|}{$25.2 \pm 10.9$} & \multicolumn{2}{|c|}{$16.1 \pm 4.3$} & $<0.0001^{*}$ \\
\hline
\end{tabular}

*= Significant, $\mathrm{N}=$ Number, $\mathrm{SD}=$ Standard Deviation,

Correlation analyses were done between Taylor Anxiety Scale scores and different clinical variables. There was significant statistical negative correlation between anxiety levels and onset of stuttering $(r=-0.48, p=0.002)$. Also, significant statistical positive correlation has been demonstrated between anxiety scores and duration of stuttering $(\mathrm{r}=0.329, \mathrm{p}=0.046)$ (Table 2$)$.

On the other hand, no significant statistical correlation was detected between anxiety grades and family history of stuttering $(\mathrm{r}=0.0061, \mathrm{p}=0.98)$. Also, no significant correlation detected between anxiety scores and stuttering severity instrument $(\mathrm{r}=0.305, \mathrm{P}=0.066)$. Moreover, correlation analyses were done between stuttering severity instrument scores and each of age of onset and duration of stuttering and revealed no statistical significant values $(\mathrm{r}=0.066$ and 0.082 respectively, $\mathrm{p}=0.698$ and 0.629 respectively (Table 2).

Table 2: Correlation Analyses between each of Taylor Anxiety scale and Stuttering Severity instrument with different stuttering-related variables:

\begin{tabular}{|c|c|c|c|c|c|c|}
\hline \multirow{2}{*}{ Variables } & \multicolumn{2}{|c|}{ Stuttering Severity instrument } & \multicolumn{2}{|c|}{ Age of onset of Stuttering } & \multicolumn{2}{|c|}{ Duration of Stuttering } \\
\hline & $\mathrm{r}$ value & $P$ value & $\mathrm{r}$ value & $P$ value & $\mathrm{r}$ value & $P$ value \\
\hline $\begin{array}{l}\text { Taylor Anxiety } \\
\text { Scale }\end{array}$ & 0.305 & 0.066 & -0.48 & $0.002 *$ & 0.329 & $0.046^{*}$ \\
\hline $\begin{array}{c}\text { Stuttering } \\
\text { Severity } \\
\text { instrument }\end{array}$ & & & -0.066 & 0.698 & 0.082 & 0.629 \\
\hline
\end{tabular}

$*=$ Significant

There were $19(54.3 \%)$ male subjects among the patients' group. They had an age mean \pm SD of $14.98 \pm 2.5$ years. Their age of onset of stuttering was at a mean age \pm SD of $6.2 \pm 2.3$ years and they had stuttering for a mean duration \pm SD of $8.6 \pm 2.5$ years (Table 3 ). Out of the male stuttering patients, 5 (26.3\%) subjects had normal anxiety scores, 4 (21.1\%) subjects had mild anxiety scores, $8(42.1 \%)$ subjects had moderate anxiety scores, and 2 $(10.5 \%)$ subjects had severe anxiety scores. Meanwhile the female stuttering subjects were $16(45.7 \%)$. Their group had an age mean \pm SD of $14.1 \pm 2.5$ years. Their age of onset of stuttering was at a mean age \pm SD of $5.3 \pm 1.5$ years and they had stuttering for a mean duration $\pm \mathrm{SD}$ of $8.8 \pm 2.8$ years (Table 3 ). Out of the female stuttering subjects, $3(18.75 \%)$ had normal anxiety scores, $4(25 \%)$ had mild anxiety scores, $7(43.75 \%)$ had moderate anxiety scores, and $2(12.5 \%)$ subjects had severe anxiety scores.

Comparison between male and female stuttering subjects regarding age of onset and duration of stuttering revealed no significant differences $(p>0.05)$ (Table3). The male patients showed stuttering severity instrument score with a mean $\pm \mathrm{SD}$ of $32.7 \pm 7.8$ and a mean $\pm \mathrm{SD}$ of Taylor Anxiety scale of $23 \pm 10.6$. Meanwhile the female patients had a mean \pm SD of stuttering severity instrument score of $35.2 \pm 6.7$ and a Taylor Anxiety Scale mean \pm SD score of $30.7 \pm 8.9$ (Table3). Comparison between male and female stuttering patients revealed no statistical significant difference regarding the SSI $(p>0.05)$. Meanwhile, Taylor Anxiety scale was significantly higher $(P<0.05)$ in the female compared to male subjects (Table 3 ). 
Table 3: Comparison between male and female stutterers regarding the different variables:

\begin{tabular}{|c|c|c|c|}
\hline Variables & $\begin{array}{l}\text { Male Stutterers } \\
\qquad(\mathrm{N}=22)\end{array}$ & $\begin{array}{c}\text { Female Stutterers } \\
\quad(\mathrm{N}=13)\end{array}$ & $\mathrm{P}$ value \\
\hline $\begin{array}{l}\text { Age of onset of stuttering } \\
\text { (Mean } \pm \text { SD) }\end{array}$ & $6.3 \pm 2.3$ & $5.3 \pm 1.5$ & $>0.05$ \\
\hline $\begin{array}{l}\text { Duration of stuttering } \\
\quad(\text { Mean } \pm \text { SD) }\end{array}$ & $8.6 \pm 2.5$ & $8.8 \pm 2.8$ & $>0.05$ \\
\hline $\begin{array}{c}\text { SSI } \\
(\text { Mean } \pm \text { SD })\end{array}$ & $32.7 \pm 7.8$ & $35.2 \pm 6.7$ & $>0.05$ \\
\hline $\begin{array}{l}\text { Taylor Anxiety Scale } \\
\quad(\text { Mean } \pm \text { SD) }\end{array}$ & $23 \pm 10.6$ & $30.7 \pm 8.9$ & $<0.05^{*}$ \\
\hline
\end{tabular}

*= Significant, $\mathrm{SD}=$ Standard Deviation, $\mathrm{SSI}=$ Stuttering Severity Instrument

\section{DISCUSSION}

The main aim of this study was to assess the difference in the anxiety levels between children and adolescents who stutter, with non stuttering subjects. The control group in the study was selected to be age and gender matched with the stuttering group. Our results showed no significant difference between both groups according to age and gender, so accordingly both groups are matched and the age and gender had no effect on the anxiety scores.

Stuttering and anxiety have different identities but they may have some sort of consequent relation. There is a hypothesis that stuttering and anxiety disorders are different specific disorders, however they may meet at an undefined point. It is a common association that stuttering patients are giving such complaints of being anxious from some specified situations that may vary from one patient to another and may increase their non-fluency condition or direct them to avoid some certain situations. This anxiety feeling induced by the stuttering situation may let stuttering subjects have this subjective anxiety that can be related to speaking situations $^{[18]}$

This study showed that $68.6 \%$ of stuttering subjects have some degree of anxiety disorder as proved by a subjective anxiety test. This is in comparison to the control group, where only $48.6 \%$ have some degree of anxiety, there was a significant difference between both groups regarding anxiety levels. This was in agreement with other similar studies that reported higher anxiety levels among children and adolescents with stuttering in comparison to non-stuttering control subjects using self-reported questionnaires ${ }^{[19-21]}$.

The likelihood of having communication difficulties and its attributes which stuttering patients face over their lifespan significantly contribute to development of anxiety disorder. It was hypothesized that anxiety increases the social burden and behavioral deficits and this may increase functional impairment ${ }^{[22,23]}$. Accordingly, there is a high risk for children and adolescents who stutter to have social and academic difficulties and being bullied compared to their fluent peers ${ }^{[20,24]}$. In their studying of anxiety levels in children between 8-14 years old, Craig \& Hancock ${ }^{[25]}$ reported that children with stuttering did not have higher anxiety levels compared to non-stuttering children. However, their studied group where comparatively of younger age than the patients and control groups of the current study. Also Beitchman et al ${ }^{[26]}$, administered psychometric interviews on adolescents at the age of 19 who were identified by different speech and language disorders in their childhood. They found no significant difference in psychometric profile including anxiety levels between children with history of speech and language problems and the control group. Their results did not provide sufficient data about the frequency of different speech disorders they included such as, number of voice, stuttering or dysarthria disorders, or a long-term follow up to state existence of the speech disorders at age of 19 years old. However, in the current study, our main concern was focused on stuttering and did not involve other speech disorders.

The results of this study also showed that there was a positive correlation between anxiety and stuttering severity instrument scores but it did not reach a significant value. This means that anxiety and stuttering have no etiological relationship but the existence of one disorder may influence the other. Number of studies reported higher anxiety scores in patients with severe stuttering than of those with a less severe stuttering ${ }^{[27,28]}$. This indicates that as the severity of stuttering increases with more visibility of the disorder and potential negative reactions by listeners, the more heightened levels of anxiety will exist. On the other hand, Blood et al, 21 did not find significant relationships between anxiety and stuttering severity. However, the effect of treatment modalities such as 
non-avoidance, desensitization and relaxation could mask the actual anxiety levels the patients might feel.

In the current study, anxiety levels showed significant negative correlation with the onset of stuttering and significant positive correlation with the duration of stuttering. This means that if stuttering starts at early age and lasts for long duration, the patient may score higher levels of anxiety. These results can be explained by that; long duration of stuttering exposes patients to implausible negative responses from their listeners, which can be reflected on their perception of anxiety. The cumulative effect of these behaviors over many years is responsible for these higher scores of anxiety as supported by previous research ${ }^{[29]}$. These reactions can develop early in preschool children who stutter as a result of bullying, teasing, exclusion and negative peer attitudes ${ }^{[30]}$. These reactions become more intensified as children grow up in school years and get involved in more difficult social and speaking situations. Accordingly, children and adolescents who stutter suffer from social isolation, rejections, peer victimization, and become less popular than their normal peers ${ }^{[31]}$. As a consequence, the results of these reactions most probably will lead to feeling of shame, embarrassment, low self-esteem, withdrawal, and low school performance ${ }^{[32]}$. These previous factors have been associated strongly with anxiety ${ }^{[33]}$ and can help in the explanation of our finding regarding the relationship between stuttering and both age of onset and duration of stuttering.

The results of this study also showed no statistical significant difference between male and female stuttering patients regarding SSI $(p>0.05)$. However, Taylor Anxiety scale was significantly higher $(P<0.05)$ in the female compared to male patients. This may be due to more exposure of adolescent females to emotional stress and anxiety than males. Despite that there are few articles studied the anxiety scores of adolescent who stutter in relation to their gender, our finding is supported by the results of Craig and Tran ${ }^{[34]}$ who concluded that female stuttering patients had consistently higher anxiety scores than male patients.

\section{CONCLUSION}

This study revealed that children and adolescents who stutter appear to have subjective anxiety disorder regarding both frequency and scores of anxiety when compared to age and gender matched control subjects. Higher anxiety scores were significantly related to both earlier age of onset and longer duration of stuttering. Stuttering and anxiety are proposed to be different disorders based on etiological background but may be mutually related and probably meet at a certain point. Female stuttering patients were more frequently subjected to higher anxiety scores in comparison to male patients.

\section{RECOMMENDATIONS AND LIMITATIONS}

Assessment of anxiety level should be considered in the primary evaluation of patients with stuttering. This possible stuttering associated anxiety disorder with better analysis and investigation as well as proper detection can help in designing the management plan of those patients. It is important to include the anxiety evaluation in the assessment protocol of stuttering, in order to detect the presence and severity of anxiety. Also, the management plan of the stuttering associated anxiety disorder, should consider the treatment of the anxiety itself through a psychiatric consultation, which could support the patient either medically or through a psychotherapy and the conventional stuttering therapy could in turn help in decreasing the level of anxiety. One of the main limitations of this study is the relatively small sample size. Thus larger scale studies are needed to establish the relationship between anxiety and stuttering and to assess the effect of speech therapy intervention on anxiety induced stuttering.

\section{CONFLICT OF INTEREST}

There are no conflicts of interest.

\section{REFERENCES}

1. American Psychiatric Association. Diagnostic and statistical manual of mental disorders. Fifth Edition (DSM-5) . American Psychiatric Association, 2013, Washington, DC.

2. Costa D, Kroll R. Stuttering: an update for physicians [review]. CMAJ. 2000; 162(13):1849-1855.

3. Prasse JE, Kikano GE. Stuttering: an overview. Am Fam Physician. 2008; 77 (9):1271-1276.

4. The stuttering Foundation; Stuttering facts and information at http://www.stutteringhelp.org/faq Available on 24.1.20.

5. Kazdin AE (Herausgeber), Encyclopedia of Psychology. Buch |Hardcover. 4160 Seiten. Oxford University Press Inc (Verlag). 2000, 978-1-55798187-5(ISBN).

6. Anxiety. Review by Mayo Clinic Staff at http://www. mayoclinic.org/diseases- conditions/anxiety/home/ ovc-20168121. Available on 24.1.2017. 
7. Barlow DH. "Unraveling the mysteries of anxiety and its disorders from the perspective of emotion theory". American Psychologist. 2000; 55 (11): 1247-63. doi:10.1037/0003-066X.55.11.1247. PMID 11280938

8. Craig A. 'The developmental nature and effective treatment of stuttering in children and adolescents' Journal of Developmental and Physical Disabilities. $2000 ; 12,3,173-186$.

9. Hancock K, Craig A, Campbell KA. Two to six year controlled trial stuttering outcomes for children and adolescents. Journal of Speech, Language and Hearing Research. 1998; 41, 1242-1252.

10. Craig AR \& Calver P. (1991) Following up on treated stutterers. Studies of perceptions of fluency and job status. Journal of Speech Hearing Research.1991; 34, 279-284

11. Menzies RG, Onslow M \& Packman A. Anxiety and stuttering: exploring a complex relationship. American Journal of Speech-Language Pathology. 1999; 8, 3-10.

12. Rifaie N. Arabicizing and Standardizing the Stuttering Severity Instrument on the Arabic Environment. Ain Shams Medical J. 1999; 50; 7, 8, 9: 907-914.

13. Riley GD. A stuttering severity instrument for children and adults. J. of Speech and hearing Dis. 1972; 37, 314-322.

14. Riley GD. Stuttering severity instrument for children and adults, revised. Ed. Manual. 1986. Austin, TX: Pro-ED.

15. Riley GD. Stuttering severity instrument for children and adults, third edition. Pro- ed. 1994. Austin, Texas.

16. Taylor JA. A Personality Scale of Manifest Anxiety. 48(2) J. Abnormal and Social Psych. 1953, 285-290.

17. Bloodstein O. The Development of Stuttering: II. Developmental Phases Journal of Speech and Hearing Disorders. 1960; 25, 366-376. doi:10.1044/ jshd.2504.366.

18. Iverach L, Jones M, O’Brian S, Block S, Lincoln M, Harrison $\mathrm{E}$, et al. The relationship between mental health disorders and treatment outcomes among adults who stutter. Journal of Fluency Disorders. 2009; 34, 1, 29-43.

19. Blood GW \& Blood IM. Preliminary study of self-reported experience of physical aggression and bullying of boys who stutter: Relation to increased anxiety. Perceptual and Motor Skills.2007; 104, 1060 1066.

20. Blood GW, Blood IM, Maloney K, Meyer, C., \& Qualls, C. D., et al. Anxiety levels in adolescents who stutter. Journal of Communication Disorders. 2007; 40, 452-469.

21. Mulcahy K, Hennessey N, Beilby J, Byrnes M, et al. Social anxiety and the severity and typography of stuttering in adolescents. Journal of Fluency Disorders. 2008; 33, 306-319.

22. Craig A, Blumgart E, \& Tran Y. The impact of stuttering on the quality of life in adults who stutter. Journal of Fluency Disorders.2009; 34, 61-71.

23. Iverach L, Jones $\mathrm{M}$, O'Brian $\mathrm{S}$, Block S, Lincoln $\mathrm{M}$, Harrison E, et al. Screening for personality disorders among adults seeking speech treatment for stuttering. Journal of Fluency Disorders. 2009; 34, 173-186.

24. Davis S, Howell P, \& Cooke F. Socio-dynamic relationships between children who stutter and their non-stuttering classmates. Journal of Child Psychology and Psychiatry and Allied Disciplines. 2009; 43, 939-947.

25. Craig A, \& Hancock K. Anxiety in children and young adolescents who stutter. Australian Journal of Human Communication Disorders.1996; 24, 28-38.

26. Beitchman J, Wilson B, Johnson C, Atkinson L, Young A, Adlaf E, et al. Fourteen-year follow-up of speech/ language impaired and control children: Psychiatric outcome. Journal of American Academy of Child and Adolescent Psychiatry.2001; 40, 75-82.

27. Fitzgerald HE, Djurdjic SB, \& Maguin E. Assessment of sensitivity to interpersonal stress in stutterers. Journal of Communication Disorders. 1992; 25, 31-42.

28. Ezrati-Vinacour R, \& Levin I. The relationship between anxiety and stuttering: A multidimensional approach. Journal of Fluency Disorders. 2004; 29, 135-148.

29. Schneier FR, Johnson J, Hornig CD, et al. Social phobia: Comorbidity and morbidity in an epidemiologic sample. Archives of General Psychiatry. 1992; 49, 282-288.

30. Langevin M, Packman A \& Onslow M. (2009). Peer responses to stuttering in the preschool setting. American Journal of Speech-Language Pathology; 2009; 18, 264-276. 
31. Blood GW, Blood IM, Tramontana GM, Sylvia AJ, Boyle MP, Motzko GR. Self- reported experience of bullying of students who stutter: Relations with life satisfaction, life orientation, and self-esteem. Perceptual and Motor Skills. 2011; 113, 353-364.

32. Langevin $M$ \& Prasad NG. A stuttering education and bullying awareness and prevention resource: A feasibility study. Language, Speech and Hearing Services in Schools. 2012; 43, 344-358.
33. Iverach L \& Rapee RM. Social anxiety disorder and stuttering: Current status and future directions. Journal of Fluency Disorders. 2014; 40, 69-82.

34. Craig A \& Tran Y. What is the relationship between stuttering and anxiety? In https://www.stammering. org/ 01.05.2005. This is a fuller version of an article appearing in the summer 2005 edition of Speaking Out. 